\title{
Questão Indígena na América Latina: Direito Internacional, Novo Constitucionalismo e Organização dos Movimentos Indígenas
}

\author{
Vivian Urquidi \\ Vanessa Teixeira \\ Eliana Lana *
}

Resumo: Neste artigo tratamos da politização da questão indígena na América Latina a partir da relação entre três elementos: o desenvolvimento do Direito Internacional, o novo constitucionalismo na região e a organização dos movimentos indígenas. Identificamos que a conjuntura interna em relação à população indígena e o modo como se constitui a esfera pública de direitos em cada país foram fatores favoráveis ao predomínio de um aspecto ou outro. Apesar disto, no cenário internacional, o conjunto dos diferentes fatores exerceu influências mútuas, fazendo com que a legislação internacional ficasse mais sensivel para a temática indígena. Por sua vez, o Direito Internacional acabou legitimando demandas históricas dos movimentos indígenas em cada país e acelerando as reformas constitucionais locais para abrigar uma cidadania étnica.

Palavras-chave: Cidadania Étnica, América Latina, Indígenas, Direitos Humanos.

Abstract: In this article we deal with the politicization of the indigenous issue in Latin America taking it as a result of the relationship of three elements: the development of the international law, the new constitutionalism in the region, and the organization of the indigenous movements. We identify that the internal situation in relation to the indigenous population and the way the public sphere of rights in each country had been constituted were favorable factors to the predominance of one of these elements over another. Despite this, in the international arena, all the three different elements exerted mutual influence making the international legislation more sensitive to the indigenous issues. In turn, international rights helped to legitimating historical demands of the indigenous movements in many countries and to accelerating local constitutional reform to recognizing ethnic citizenship.

Keywords: Ethnic Citizenship, Latin America, Indigenous People, Human Rights.

\footnotetext{
* Vivian Urquidi: Professora da Universidade de São Paulo no Programa de Pós-Graduação em Integração da América Latina (PROLAM/USP) e na Escola de Artes, Ciências e Humanas (EACH/USP). E-mail: vurquidi@usp.br. Vanessa Teixeira: Mestranda do Programa de Pós-Graduação em Integração da América Latina (PROLAM/USP). E-mail: vanessacgteixeira@ yahoo.com.br. Eliana Lana: Mestranda do Programa de Pós-Graduação em Integração da América Latina (PROLAM/USP). E-mail: elianaslana@hotmail.com. Recebido em 08/06/08 e aceito em16/06/08.
} 


\section{Introdução}

Em setembro de 2007, na Assembléia da ONU, os países reunidos aprovaram a Declaração Universal dos Direitos dos Povos Indígenas, encerrando mais de duas décadas de debates e justificativas na busca de ampliar direitos individuais para uma nova categoria de sujeitos considerados agora coletivamente. A Declaraçấo avança assim para o reconhecimento dos povos indigenas como naçôes preexistentes aos Estados nacionais republicanos, outorgando a suas demandas a legitimidade necessária para exigir de cada governo a efetivação dos seus direitos.

Na América Latina, a Declaração adquire particular importância porque a regiáo abriga $10 \%$ do contingente indígena do mundo. Nesta região, as estimativas avaliam que a populaçáo de indígenas oscila entre 8 a $12 \%$, o equivalente entre 30 e 50 milhóes $^{1}$ de pessoas, acumulando altos índices de mortalidade, analfabetismo e incidência de extrema pobreza (CEPAL, 2006a, 2006b; PNUD, 2004).

Em alguns países como a Guatemala, a Bolívia, o Peru e o Equador, a população indígena equivale, e pode até superar, à dos indivíduos não indígenas. Em outros, a superfície habitada por comunidades indígenas é considerada proporcionalmente superior à ocupada pelo resto da sociedade. No caso brasileiro, por exemplo, uma população indígena de $0,4 \%$ (CEPAL, 2006b) ocupa mais de 12\% do território nacional (BARIÉ, 2003; MARÉS, 1998), um espaço particularmente rico em biodiversidade, recursos hídricos, madeiras preciosas e jazidas de minérios, exigindo do governo repensar o relacionamento com os povos indígenas como base para o desenvolvimento estratégico nacional.

A temática indígena é então um problema de ordem política, e não mais apenas uma questão étnica, antropológica ou social, a ser considerada pelos Estados dentro da formulação e implementação de políticas públicas. Por outro lado, no mundo contemporâneo, o direito dos povos indígenas não se restringe à política interna de cada país, mas vem se transformando em normas de ordem pública internacional que cada país deve aplicar em escala local (CEPAL, 2006b).

\footnotetext{
${ }^{1}$ Os dados demográficos da população indígena oscilam de acordo aos critérios censitários utilizados. A origem étnica pode estar definida em cada país por uma ou mais das seguintes variáveis: fenótipo definido pelo pesquisador, autodeclaração de origem ou pela língua mãe.
} 
Nesse contexto, as instituiçóes internacionais de desenvolvimento e direito querem saber quem são, quantos são e onde estão os povos indígenas, como um "insumo" básico para as políticas e os programas de desenvolvimento humano, cientes de que a situação de cada grupo depende tanto do seu peso demográfico como de seu poder político. Conseqüentemente, a questão étnica tem se transformado em assunto político a repensar, nacionalmente, questóes de território e recursos naturais, aspectos de identidade e de reconhecimento da diversidade, problemas de educação e expressão cultural, e principalmente demandas por autonomia e participação nas decisóes que afetam os povos indígenas.

A teoria sócio-política observou que a politização recente das questóes étnicas resulta de uma confluência de no mínimo três aspectos que atuam de modo interligado: (a) o desenvolvimento do Direito Internacional, caracterizando os direitos indígenas como parte específica dos Direitos Humanos; (b) a emergência de movimentos indígenas que atuam, nacional e internacionalmente, cada vez mais como grupos de interesse dentro da sociedade civil e nos espaços públicos democráticos, pressionando por uma nova leva de direitos coletivos; e (c) os processos recentes de reformas constitucionais em vários países, reconhecendo - pelo menos em princípio - o caráter multiétnico de suas sociedades (SIEDER, 2002).

Neste trabalho analisamos o desenvolvimento de cada um destes fatores, considerando sua incidência em alguns países da América Latina. Sabe-se que, apesar de os três aspectos estarem correlacionados, a conjuntura interna de cada país em relação à população indígena e o modo como se articula a esfera pública de direitos são fatores que fizeram predominar um aspecto sobre os outros: ora o fator mais importante foi a mobilização indígena, ora foi a iniciativa governamental em fase de abertura democrática com um viés social, ora foram as pressôes internacionais facilitando a expressão da diversidade local.

Pretende-se analisar aqui o processo de transformação política da questão étnica na América Latina, com destaque em alguns países da região, contribuindo assim para a compreensão das demandas dos povos indígenas e das alternativas que estáo sendo consideradas para superar sua situaçáo marginal dentro dos Estados nacionais. 


\section{Ampliação do Direito Internacional e inclusão dos Direitos Indígenas}

O desenvolvimento do Direito Internacional em matéria indígena ocorreu de modo lento e gradual ao longo do século XX, num processo direcionado para superar a clara ênfase individualista dos Direitos Humanos apesar da Declaraçâo Universal, de $1948^{2}$, e o caráter integracionista das políticas locais e dos acordos intergovernamentais.

$\mathrm{Na}$ América Latina, as primeiras açóes formais no plano internacional relativas à legislação indígena foram orientadas sob o indicativo da integração das populaçôes indígenas e remontam ao $1^{\circ}$ Congresso Indigenista Interamericano de Pátzcuaro, de 1940, no México, numa tentativa de articular a legislação indigenista, tendo em mente sistematizar e comparar os princípios jurídicos e a legislação dos países membros.

Posteriormente, com o mesmo espírito integracionista, em 1957, a Organização Internacional do Trabalho (OIT), mediante o Convênio 107 sobre Populaçôes Indígenas e Tribais adotou diversas proposiçôes de caráter obrigatório para os países signatários, tendo como objetivo orientar as açóes dos governos em matéria indígena. No preâmbulo, o acordo explicita como alvo das açôes as populaçôes "que não estão integradas ainda na coletividade nacional” (grifo nosso). Nesse contexto, apesar de o Convênio 107 avançar em questôes como a promoção de direitos consuetudinários, de línguas originárias e a designação de terras tradicionais, o convênio incumbe os governos a desenvolver programas com o objetivo de facilitar a integração progressiva das comunidades indígenas no país.

Sem o caráter obrigatório do Convênio, mas estabelecendo um sistema

\footnotetext{
${ }^{2}$ A Declaração afirma a importância dos direitos sociais, econômicos e culturais. No entanto, os Estados sempre deram mais atenção aos direitos individuais, nesse sentido, a própria repreensão realizada no plano internacional com relação à violação de direitos humanos se dava muito mais para afirmar a necessidade de cumprimento dos direitos individuais e políticos, deixando os direitos econômicos, sociais e culturais em segundo plano. Num longo processo que ocorreu nas décadas seguintes à Declaração, as Nações Unidas tentaram afirmar a importância central dos direitos econômicos, sociais e culturais, e a interdependência entre as chamadas gerações de direitos humanos. O primeiro esforço nesse sentido se deu com a aprovação pela Assembléia Geral dos dois Pactos, sobre os Direitos Civis e Políticos e sobre os Direitos Sociais, Econômicos e Culturais, ambos em 1966, que detalhavam e especificavam a importância dos direitos de ambas naturezas. Por fim, em 1993, as Nações Unidas realizaram a Convenção de Viena em que se reafirmava a interdependência entre os direitos civis e políticos (individuais) e os sociais, econômicos e culturais (de caráter coletivo, difuso ou intergeneracional). Sobre os Pactos de 1966, vide COMPARATO (2001), especialmente cap. 18.
} 
de princípios de validade pretensamente universais, amparado no consenso dos países signatários, a Declaração Universal dos Direitos Humanos, de 1948, acrescenta alguns elementos utilizados pelos povos indígenas para a fundamentação de seus direitos. O primeiro tem como base a necessidade de ampliar a proteção gerada pelos direitos individuais -os princípios de igualdade e não-discriminação, por exemplo- para abrigar grupos ou comunidades de pessoas -coletividades- e considerá-las em conjunto como sujeitos de direito, e assim tratar aspectos como de propriedade coletiva da terra.

$\mathrm{Na}$ mesma esteira de desafio, os povos indígenas têm buscado fazer reconhecer um direito de autodeterminação em relação ao Estado, para questóes como organização, escolha de autoridades, administração de justiça e autonomia sobre seu território e recursos, fundamentando-se na sua situação pré-existente ao estatuto colonial.

Um documento importante que trata deste aspecto é o Convênio 169 sobre Povos Indigenas e Tribais em Países Independentes. O Convênio assinado na OIT, em substituição ao Convênio 107, é considerado atualmente a ferramenta de caráter obrigatório mais eficaz e avançada em matéria de direitos indígenas. São vários os aspectos que indicam a sua relevância. Em princípio, o documento determina a consciência da identidade como critério para a definição do sujeito do direito, considerando, ainda, a identificação dos grupos como povos, o que resulta num discernimento de direito coletivo.

O Convênio destaca ainda a relevância da participação dos indígenas nas decisóes que possam afetá-los, expressando a idéia central de que os povos indígenas devem ter a possibilidade, garantida pelas políticas públicas nacionais e pela estrutura jurídica de cada país, de decidir os rumos de sua vida social, cultural e econômica. Promove, assim, a educação na língua original e com conteúdos, em princípio, a ser definidos pelas próprias comunidades.

Reconhece também o direito aos recursos naturais das terras tradicionais (utilização, administração e conservação), considerando que nos casos em que pertencer ao Estado a propriedade dos recursos existentes nas terras, seu uso deverá estar embasado em consultas aos povos interessados, reservandose a eles a indenização por efeitos danosos que possam advir desse uso. Parte importante desse direito central é a garantia dos territórios tradicionais pelo respeito que os governos deverão ter da relação especial e dos valores 
espirituais que os povos dão às suas terras ou territórios, reconhecendo os direitos de propriedade e posse das terras que esses povos tradicionalmente ocupam.

Tais garantias parecem introduzir o princípio de autodeterminação de uma forma específica no sentido do rumo da vida das comunidades; entretanto, não aceitam o direito à autodeterminação dos povos no sentido do direito internacional, conforme anuncia no preâmbulo a Convênção: "A utilização do termo 'povos' neste Convênio não deverá interpretar-se no sentido que tenha implicação alguma no que atinge os direitos que possa conferir-se a tal termo no direito internacional', isto é, na possibilidade de buscar uma soberania dentro da forma política de Estado-Nação.

A influência do Convênio 169 é marcante nos países da América Latina, inclusive em razão das reformas constitucionais introduzidas no tema em pauta. No México, por exemplo, o Convênio foi base para que os movimentos indígenas organizassem suas demandas e questionassem a reforma constituinte, à luz da legalidade do acordo de San Andrés (BUENROSTRO, ARELLANO, 2002). Já na Guatemala, a assinatura do Acordo de Paz com o governo foi condicionada pelos grupos rebeldes indígenas à ratificação pelo Estado do Convênio 169. No Chile, por outro lado, a pressão para a ratificação do Convênio (algo que somente ocorreu em março de 2008) funcionou como elemento de articulação interna para as organizaçóes indígenas (MARIOTTI, 2004).

Finalmente, o Convênio está na base da Declaração de Direitos dos Povos Indigenas, assinada em 2007, influenciando o entendimento da questão étnica em termos menos conflituosos com as demandas contemporâneas dos indígenas.

A Declaração expressa formalmente o direito à autonomia e ao autogoverno dos povos em questóes relacionadas com seus assuntos internos e locais, destacando $o$ direito a dispor dos meios para financiar suas funçóes autônomas. Além de adotar os critérios da 169 em matéria de direitos sociais e culturais, a Declaração destaca o direito destas populaçóes a decidir, junto com o Estado, sobre os recursos naturais nos seus territórios, e sobre o exercício da justiça comunitária, de acordo com seus valores e tradiçóes ancestrais, legitimando assim suas autoridades locais.

Por fim, afirma o direito dos povos de manter, controlar, proteger e 
desenvolver sua propriedade intelectual e seu patrimônio cultural, o que lhes permite reivindicar benefícios para seus conhecimentos tradicionais, sua ciência, tecnologias e suas culturas, além de manter uma educação bilíngüe e de conteúdos multiculturais.

De acordo com o relatório da CEPAL (2006b), as normas internacionais básicas relativas aos direitos coletivos dos povos indígenas, no contexto de desenvolvimento da cidadania étnica respondem às categorias de direitos (a) a não discriminaçẫo; (b) a integridade cultural; (c) de propriedade, uso, controle e acesso às terras, territórios e recursos; (d) de desenvolvimento e bem-estar social e, (e) de participação política, consentimento livre, prévio e informado.

Assim, enquanto o 169 é o instrumento de caráter obrigatório mais avançado, a Declaração será o documento de princípios mais ousado a respeito dos direitos indígenas e a síntese dos debates, conceitos e princípios sobre o assunto, reunindo o âmago das demandas das comunidades.

Entretanto, por ser documentos de princípios, as Declaraçōes representam apenas obrigação moral, ou no máximo política, aos Estados conveniados (BOBBIO, 2004). Conseqüentemente, os povos indígenas se vêm permanentemente forçados a se mobilizar para ter incorporados seus direitos na legislação interna de cada país.

Se por um lado, a Declaração de 2007 foi motivo de comemoraçáo nas comunidades indígenas, por outro ela gerou também fortes resistências para sua aprovaçáo sob o argumento dos riscos à unidade nacional e à soberania territorial de cada país, caso os princípios fossem levados à risca.

A despeito desse debate, que não é recente, o consenso dos 143 Estados que ratificaram a Declaração indica que esta constitui um documento-base a partir do qual os movimentos indígenas em cada país poderáo negociar com o Estado as condiçóes de realizaçáo das suas demandas. Em outras palavras, a Declaração passa a ser um documento de princípios e também de orientação político-jurídica futura das açóes de um movimento social e do próprio Estado.

A organizaçáo indígena e a ação coletiva, conforme observaremos, se nutriram amplamente dos princípios do Direito Internacional para fortalecer suas demandas, mas também foram fundamentais para o avanço na compreensão de novos direitos no âmbito internacional da discussão. 


\section{Organização indígena e cidadania étnica}

De modo mais ou menos geral, os indígenas na América Latina assumiram sua forma de organização política atual em relação ao Estado e à sociedade ao longo das últimas quatro décadas do século $\mathrm{XX}$, conseguindo em alguns países, até a década de 90, que suas ações ganhassem impacto nacional, quando não internacional.

Da mesma forma, muito embora as demandas reproduzam questóes históricas que a memória coletiva dos povos indígenas insiste em trazer desde o estatuto colonial -autonomia e posse da terra, por exemplo-, o teor atual do debate sintetiza em grande medida a formulação dos princípios discutidos e articulados no plano internacional.

De acordo com este processo de desenvolvimento do Direito Internacional, observam-se também na América Latina transformações institucionais e da esfera pública que culminaram, na década de 90, em processos de reformas constitucionais com vistas à democratização e à ampliação da participação social na vida política do país. Especificamente, em relação às minorias étnicas, a influência da Convenção 169 deu base jurídica específica à questão, fornecendo novo fôlego à organização das comunidades indígenas em agrupamentos diversos, capazes de interpelar o Estado, exigindo dele políticas sociais para a superação da pobreza, maior participação na tomada de decisôes e inclusive reconhecimento das identidades indígenas como parte da identidade nacional: a Colômbia, em 1991, incorporou a diversidade étnica e cultural na sua constituição; em 1992, o México oficialmente assumiu sua composição multicultural; o Paraguai, em 1992, além do reconhecimento dos direitos indígenas, se auto-intitulou como país bilíngüe; o Peru, em 1993 aprovou, ao lado do castelhano, as línguas indígenas como oficiais; e, em 1994, a Bolívia incorporou na Constituição sua plurietnicidade. A Argentina foi um pouco mais tímida a respeito, admitindo unicamente a pré-existência de povos indígenas (MARÉS, 2003).

Nesse contexto, nas últimas décadas do século XX a temática indígena sofreu mudanças substantivas entre as quais a consolidação dos movimentos indígenas como atores políticos foi uma das mais notáveis, exigindo mudanças significativas nas políticas públicas das democracias dos países latino-americanos (CEPAL, 2006b). 
A teoria social chamou a este fenômeno coletivo de Novos Movimentos Sociais (LARAÑA, GUSFIELD, 1994; GOHN, 1997; LARAÑA, 1999; SANTOS, 2005) - movimentos étnicos e de gênero, dentre outras minorias-, que surgem nas últimas décadas, ocupando o espaço tradicional dos movimentos de classe, cada vez menos influentes no cenário político e social por causa das transformaçóes econômicas globais e do desmonte da estrutura sindical.

$\mathrm{Na}$ América Latina, de modo mais ou menos geral, os novos movimentos sociais surgiram com o fim das tensóes políticas da fase de governos autoritários e de pactos populistas em torno dos militares das décadas de 60 e 70 . A volta à democracia, a formação de uma nova esfera pública de atuação da sociedade civil, além da recuperação dos princípios de cidadania e civilidade, facilitaram a repolitização dos problemas cotidianos, entre os quais as questóes étnicas e de identidade cultural. Paralelamente, o Estado, pressionado para assumir um caráter público mais amplo e de instituições mais democráticas, facilitou a participação dos setores organizados em instâncias intermediárias do poder.

As ações coletivas de maior envergadura na região foram por luta pela terra, e também pela satisfação das necessidades básicas de educação, saúde, trabalho e moradia (GOHN, 1997). Em muitos casos, as minorias étnicas indígenas desempenharam papéis importantes no centro das açóes e da organização social, como ocorreu na Bolívia e no Equador, ou no caso do neozapatismo mexicano da década de 90.

De modo geral, a mobilização indígena é resultado de experiências políticas de organização e enfrentamento de décadas, e de uma série de articulações com outros setores da sociedade. Foi o caso dos movimentos de base junto à igreja no Peru, por exemplo; da aliança social com os sindicatos operários na Bolívia, ou do trabalho conjunto com as organizaçóes não-governamentais no Brasil e na Colômbia. Na Guatemala, por sua vez, uma parte dos indígenas maias atuou articuladamente com movimentos armados de resistência civil e intelectuais de esquerda à ditadura militar. Como resultado, tem-se uma ampliação das bandeiras indígenas, incorporando demandas políticas de outros atores sociais do país, que favoreceram a consolidação da cidadania étnica. Paralelamente, outros setores da sociedade incorporam, dos indígenas, princípios de identidade e defesa que favorecem a reconstrução da noção 
abstrata de nação (ANDERSON, 1997).

Observa-se assim uma articulação diversa em torno dos povos indígenas dentro do cenário específico de cada país e das suas situações conjunturais internas. Numa tentativa de estabelecer um padrão regular entre eles, podese afirmar que suas açóes de modo geral têm sido pela recuperaçâo da terra, via reforma agrária ou pela delimitação e titulação de territórios, como alternativa de sobrevivência econômica, social e cultural, quando não de reinserção social. Entretanto, crescentemente eles têm buscado, também, se reafirmar politicamente no território que ocupam e nacionalmente, demandando níveis de autonomia local ou de partilha de poder nas instituiçóes formais do Estado. A retórica da valorização cultural também tem favorecido a articulação interna e a melhor identificação dos sujeitos de cidadania étnica.

Alguns casos de atuação indígena na política nacional foram mais notáveis na história latino-americana contemporânea. A Confederación de Nacionalidades Indígenas del Ecuador (CONAIE), por exemplo, é um caso a ser acompanhado nas origens, na década de 80. Desde então, a CONAIE tem se destacado pela promoção de açóes de defesa das nacionalidades indígenas, ameaçadas pelas políticas de reestruturação econômica no país ao ampliar as fronteiras de exploração de minérios e de hidrocarbonetos nas suas regiôes. Também se organizaram em direção ao Estado, no sentido de ocupar concretamente espaços no Congresso e no Executivo, pela via da representação política: em 1996 a CONAIE, articulada com movimentos sociais urbanos na Coordenadoría de los Movimientos Sociales (CMS), constituiu o primeiro instrumento político indígena equatoriano, o partido Pachakutik ${ }^{3}$, servindo de imediato para a fratura do bloco hegemônico e a renúncia de Abdalá Bucaram da presidência do país; em 1998, pressionando para a criação de uma Assembléia Constituinte, o movimento conseguiu a ampliação dos direitos dos povos indígenas (embora ainda não fosse admitida a plurinacionalidade do Estado); em 1999, três revoltas indígenas desmontaram as políticas de ajuste estrutural do governo; em 2002, já reconhecido como sujeito político legitimado, o movimento Pachakutik elegeu Lucio Gutierrez e chegou a fazer parte do governo, mas três anos mais tarde, pressionou para sua renúncia ao constatar que Gutierrez retomara alianças com o bloco político conservador do Equador (GUERRERO, 1996;

${ }^{3} \mathrm{O}$ nome do partido é Movimento de Unidad Plurinacional Pachakutik-Novo País (MUPP-NP) 
GALLEGOS, 2001; GARCÍA SERRANO, 2001). Finalmente em janeiro de 2007, o movimento constituiu a base de uma nova aliança popular que garantiu a Rafael Correa a presidência do país, iniciando no mesmo ano um processo constituinte cuja missão seria, entre outros aspectos, colocar as bases da plurinacionalidade do Estado.

A originalidade da agenda deste movimento, em comparação às mobilizações indígenas históricas, consistiu no fato de ele colocar questóes de cidadania étnica e de interesse imediato ao setor indígena, como reforma agrária, por exemplo, junto a uma oposição consistente contra as reformas estruturais, ou a defesa do processo democrático popular, com o que os indígenas conseguiram angariar alianças com setores não indígenas e sentar as bases de um novo bloco hegemônico.

Semelhante ao caso equatoriano, o movimento indígena boliviano também alcançou uma posição central no cenário político nacional, fazendo confluir demandas das minorias étnicas junto a questóes mais amplas da vida econômica e política nacional (URQUIDI, 2007).

As experiências equatoriana e boliviana expressam uma vontade estatal -no sentido de determinação para assumir o poder do Estado- distinta com relação às ações de resistência do passado e também diferente ao levante armado do Ejército Zapatista de Liberación Nacional (EZLN), no México, que, em 1994, tomou várias cidades de Los Altos de Chiapas. A insurreição fez coincidir o levante dos indígenas com o primeiro dia da entrada em vigor do Tratado de Livre Comércio, subscrito pelo México, sendo que a finalidade política do movimento não foi a mudança da estrutura de poder, mas o diálogo com o governo para compeli-lo a introduzir mudanças sociais na região e também a aceitar um nível de autonomia da comunidade (SAINTPIERRE, 2000; BUENROSTRO, ARELLANO, 2002).

$\mathrm{Na}$ Bolívia e no Equador, pelo contrário, o projeto de avançar em direção ao Estado e assumir nele uma posição política e sob comando dos movimentos indígenas exigiu açóes coordenadas junto a outros setores populares e de esquerda, até constituir os instrumentos políticos Pachakutik no Equador e Movimiento al Socialismo, na Bolívia. Neste último país, como conseqüência da ação coordenada entre indígenas plantadores da folha de coca, trabalhadores mineiros e urbanos, além de setores das classes médias, 
deu-se a eleição do líder do movimento, Evo Morales, como o primeiro presidente indígena no mundo. Resulta também deste processo, a instalação de uma nova Constituinte, em julho de 2006, numa ação qualificada como a refundação do país a partir de uma cidadania étnica.

Cabe destacar nestas duas experiências, como no caso dos indígenas chiapanecos, que o desenvolvimento de uma consciência de direito deu-se em meio à pobreza extrema das suas populaçóes ${ }^{4}$, aspecto que embora não seja característica apenas dos indígenas nestes países, permite concluir que não há correspondência obrigatória entre o nível de desenvolvimento social e material de um grupo e o grau de consciência adquirido a partir de suas necessidades e de seus direitos.

Assim, as experiências acima indicadas são importantes, mas estão longe de traduzir a diversidade de situaçóes que os indígenas na América Latina enfrentam no cenário local das lutas sociais. No Peru, por exemplo, os movimentos indígenas independentistas do século XIX são vanguardistas em relação ao resto do continente, mas atualmente eles têm tido dificuldade em conseguir uma unidade real das facçóes e definir uma posição em relação ao Estado porque seu desenvolvimento foi prejudicado na década de 80 pela ação da guerrilha maoísta do Sendero Luminoso (GUERRERO BRAVO, 2004) nas áreas rurais e, posteriormente, pela emergência do narcotráfico e pelas políticas neoliberais da era Fujimori.

No caso colombiano, também, a violência e os conflitos sociais gerados pela guerra civil e a presença da guerrilha, das forças armadas e paramilitares nos territórios indígenas constitui o problema de maior urgência e importância neste momento, pois têm gerado um elevado índice de vítimas coletivas entre os indígenas (STAVENHAGEN, 2008). A despeito da violência da guerra na Colômbia, foi a posse da terra o fator que articulou o movimento indígena contemporâneo, a partir de 1992, quando o governo colombiano iniciou um processo de expropriação de terras consideradas de utilidade pública, para a construção de hidrelétricas e exploração do petróleo. O paradoxal deste caso é que desde 1991, o país tem uma das legislaçóes mais avançadas em direitos indígenas do continente e por isso poucas vezes foi questionada

\footnotetext{
${ }^{4}$ No Equador, a incidência de pobreza nas populações indígenas é de 89 \% (CÓNDOR, 2006), já na Bolívia, a pobreza indígena nas áreas rurais atinge mais de 80\% da população, sendo que $55 \%$ vive em situação de extrema pobreza (INE, 2002).
} 
pelo movimento indígena em busca de maior abertura a suas demandas. Entretanto, dada a expressão minoritária dos indígenas na Colômbia, em termos qualitativos e quantitativos deste setor (2\% [CEPAL, 2006b] da população é indígena), sua capacidade de pressão fica muito limitada e sua situação tende a passar despercebida no país (ARENAS, 2003).

$\mathrm{O}$ quadro geral da organização coletiva indígena na América Latina é, assim, diverso. Mistura níveis distintos de articulação em relação ao Estado e diferente capacidade de pressão no meio das histórias locais dos conflitos. Num cenário heterogêneo de demandas, entretecem-se graus distintos de luta pela sobrevivência, ora por interesses imediatos, como acesso a terra, ora por aspectos mais amplos do âmbito da sobrevivência cultural, ora confrontos no plano nacional que envolvem interesses econômicos globalizados.

Em qualquer dos casos citados, as açóes coletivas aqui sintetizadas são um fenômeno recente que têm ganhado legitimidade quando sustentadas em princípios e direitos internacionalmente reconhecidos. Não cabe aqui determinar a anterioridade de um fenômeno em relação ao outro. Em alguns casos, a mobilização pode resultar da acumulação histórica de experiências contra a invasão das terras indígenas, desde tempos coloniais, constituindo o repertório inicial e original das demandas por direitos diferenciados para os povos indígenas. Em outras situações, a violência à que as comunidades foram submetidas fraturou o eixo da organização social, atrasando até a abertura democrática do país, o despertar da organização indígena. Em outras situaçóes, finalmente, foi o impulso das energias externas que organizou as alianças e definiu horizontes de luta para os movimentos.

Em todo caso, estas transformaçóes exigiram a adaptação do quadro normativo interno nos países, aspecto que trataremos no que se segue.

\section{Direito Indígena nos sistemas nacionais}

Em países onde a presença estatal é maior, como no Canadá e na França, a complexidade social que resulta da presença de minorias nacionais ou étnicas tem sido tratada mediante a discussão sobre seus direitos civis e políticos como indivíduos, assegurando-lhes as liberdades de organização política, de culto e de expressão cultural. Mesmo assim, as minorias exigiram do Estado açóes mais ativas no sentido de garantir a cidadania diferenciada por 
meio de medidas legislativas e/ou constitucionais específicas que, para além dos direitos comuns, introduzam direitos adaptados às suas necessidades particulares de grupo (KYMLICKA, 1996).

Nas sociedades latino-americanas, pelo contrário, os direitos que conformam a cidadania civil, política e social das comunidades indígenas têm sido sistematicamente ignorados. Estatísticas demonstram que nestas sociedades, as comunidades indígenas possuem índices sociais muito abaixo do resto da sociedade (RENSHAW, WRAY, 2004; CEPAL, 2006b; PSACHAROPOULOS, PATRINOS, 1994), e que a ausência de programas de registro civil dificulta a definição de políticas sociais pelo Estado, impedindo parte desta população de ter acesso à educação ou de exercer seu direito ao voto: "É necessário ressaltar que até a década de 80, com raras exceçóes, as Constituiçôes latino-americanas nem sequer se referiam aos direitos dos povos indígenas, alguns países criaram um sistema jurídico à margem da diferença étnica, como a Bolívia, de maioria de população indígena, que somente alterou a situação na reforma constitucional de 1994" (MARÉS, 1998, p. 185).

Contudo, ao longo da década de 1990, ocorreu na região um importante processo de disseminação de políticas estatais de cidadania étnica, para o que um intenso processo de reformas constitucionais foi iniciado, inserindo em maior ou menor medida, os princípios do direito internacional e os da Convenção 169.

De acordo com Barié (2003, p. 87) o re-ordenamento constitucional dos países latino-americanos das últimas décadas pode ser classificado de acordo com o grau de adesão às Convençôes internacionais e Declaraçóes, e pela abrangência dos direitos reconhecidos. Identificam-se três grupos de Estados e níveis de envolvimento deles com os direitos indígenas:

(a) Estados que não se preocupam em incorporar nas suas leis fundamentais direitos para as minorias étnicas, nem possuem o conceito de indígena nas suas constituições. Eles são o Belize, o Chile5, a Guiana Francesa, o Suriname e o Uruguai. São países ou com tradição legal de influência anglo-saxônica, que desconsidera a heterogeneidade social da sua comunidade nacional,

\footnotetext{
${ }^{5}$ Somente em março de 2008, o Chile assinou o Convênio 169 sobre Povos Indígenas e Tribais em Países Independentes, com 18 anos de atraso.
} 
ou que não renovaram suas constituiçóes, inspirados ainda no liberalismo individualista e universalista do século XIX,

(b) Estados que constitucionalmente outorgam algum tipo de proteção pontual a seus grupos étnicos, mas dentro de um marco legal incompleto ou pouco articulado, e que geralmente têm um enfoque evolucionista e assimilacionista. Estes países são a Costa Rica, El Salvador, a Guiana e Honduras. Finalmente,

(c) Estados que incorporaram uma extensa legislação indigenista nas Constituições, embora com profundidade e abrangência diversas. Eles assumem responsabilidades em relação a suas comunidades e fixam certas regras para permitir a sobrevivência cultural e a proteção dos territórios indígenas. São países que recentemente incorporaram as demandas de cidadania étnica: a Guatemala (1986), a Nicarágua (1987 e 1995) e o Brasil (1988). Além destes países, compóem este grupo a Argentina e o Panamá (1994), a Bolívia (1995), a Colômbia (1991), o Equador (1998), o México (1992 e 2001), o Paraguai (1992), o Peru (1993) e a Venezuela (1999).

Cabe destacar que o espírito das experiências constitucionais do Brasil (1988) e da Nicarágua (1987) teve influência na Convenção 169 (BARIÉ, 2003), principalmente na abertura da esfera pública de debate, facilitando a participação direta da sociedade em assuntos que a atingem. Entretanto, as constituiçóes que mais avançaram para incorporar os direitos indígenas foram a Colômbia e a Venezuela. Nesses países, é possível constatar que, embora exista um percentual reduzido de indígenas, $2 \%$ e 2,3\% respectivamente, para dados de 2000 (CEPAL, 2006b), uma avançada legislação indígena foi desenvolvida em questóes de reconhecimento de territórios, participação política, autonomia e promoção cultural, além de proteção do etnoconhecimento (BARIÉ, 2003).

$\mathrm{O}$ avanço no campo de direitos humanos na Venezuela deve ser compreendido no marco da Constituição de 1999, sob o governo de Hugo Chavez, e no espírito social da Carta, que recolhe as experiências jurídicas mais importantes da América Latina e elabora um documento com participação dos indígenas na elaboração dos direitos. Já o caso da Colômbia parece responder à experiência legislativa do país, desde o século XIX, favorecendo as populações indígenas em assuntos diversos, como a isenção de impostos 
(BARIÉ, 2003).

Também são casos interessantes países como a Bolívia e o Equador, onde há uma elevada mobilização indígena -uma população estimada entre $50 \%$ e $70 \%$ no caso boliviano, e $25 \%$ a $35 \%$ para o Equador ${ }^{6}$ (CEPAL, 2006b) - organizada como grupo de pressão para a instalação de processos Constituintes que sejam capazes de reconhecer o caráter plurinacional das suas sociedades e a necessidade de descentralizar o poder estatal.

Desse modo, o novo constitucionalismo pluralista destaca o reconhecimento dos povos indígenas como sujeitos políticos e não apenas como objetos de políticas ditadas por outros. Aceita a identidade do Estado-nação como multiétnica e pluricultural, o direito individual e coletivo à própria identidade e o reconhecimento do pluralismo jurídico (STAVENHAGEN, 2008). Entretanto, a implementação deste processo institucional, o desenvolvimento e adaptação da justiça e da lei, e o acesso e a apropriação dos indígenas aos novos instrumentos tem sido desigual na regiâo.

Assim, se por um lado houve crescimento na participação direta dos indígenas no poder estatal e nos órgãos nacionais de representação no Equador e na Bolívia, em outros países, como a Colômbia e a Venezuela, foi preciso ainda adotar medidas para garantir a participação de indígenas no Congresso, mediante cotas de representação. No resto dos países, a ausência de preocupação com o assunto impede a ampliação dos espaços públicos de participação indígena.

O livro que sintetiza os sete informes anuais (2002-2007) do relator especial Rodolfo Stavenhagen (2008) para os Direitos Humanos e Liberdades Fundamentais dos Indigenas, apresentado no Conselho de Direitos Humanos da ONU, observa a brecha entre as normas e princípios internacionais e a legislação nacional, muito embora a ratificação dos convênios seja quase generalizada na região: há inconsistência legal, ausência de leis secundárias

\footnotetext{
${ }^{6}$ Nos dados oficiais do Equador, publicados pela CEPAL em 2006, a população indígena neste país é apenas de 6,8\%, mas esta informação tem sido contestada por outras fontes de dados apresentada pela própria CEPAL: o Centro Cultural AbyaYala afirma em estudo publicado em 2006 que a população indígena alcançaria 25\%, já de acordo com a Coordinadora Andina de Organizaciones Indígenas para o mesmo ano, a população indígena alcançaria 35\% da população nacional . Este último dado é corroborado no estudo de Jordán Pando (1990), sobre Poblaciones Indígenas de América Latina y el Caribe (CEPAL, 2006b).
} 
ou regulamentos e falta capacitação especializada de pessoal, por carência de recursos ou de vontade política, o que deixa a administração pública sem meios jurídicos e práticos para cumprir com os acordos internacionais.

Assim, por exemplo, muito embora a constituição venezuelana (1999) crie organismos públicos diversos encarregados da promoção e garantia dos direitos dos povos indígenas, ainda não aprovou a Ley Orgánica de los Pueblos y Comunidades Indígenas que deveria regulamentar os avanços constitucionais. A constituição equatoriana (1998), pelo seu lado, reconhece a multietnicidade e pluriculturalidade do Estado, o pluralismo jurídico, os direitos coletivos sobre a cultura, idioma, território e organização, além das autoridades próprias e da administração de justiça indígena, mas não dotou de uma lei orgânica capaz de regulamentar a prática desses direitos. O significativo é que já iniciou um novo processo constituinte em 2007. A Constituição colombiana (1991) reconhece a coexistência do direito indígena com a jurisdição ordinária do direito positivo, mas a falta de compatibilidade entre elas exige constantemente que a Corte Constitucional dirima a inconsistências entre ambas as jurisdiçóes. De modo semelhante, a Constituição boliviana de 1994 afirma o caráter multiétinco e pluricultural do país, bem como protege os direitos sociais, econômicos e culturais dos povos indígenas, além de reconhecer as terras originárias e a administração de funçóes e justiça comunitária. Apesar disto, o relatório de Stavenhagen (2008) observa que muitos destes direitos somente têm tido efeitos no plano formal normativo, sem impacto prático nas comunidades.

Já em outros países da região, como na Guatemala, a Constituição de 1986 reconhece a cidadania étnica em matéria cultural e posse da terra, mas a lei orgânica ainda não se adaptou aos direitos indígenas. Do mesmo modo, o acordo de paz sobre direitos e cultura indígena, assinado em 1995 entre as comunidades indígenas e o governo, deveria ter sido elevado a estatuto constitucional, mas a proposta foi rejeitada em 1999 em referendo e sua implementação foi suspensa.

Nos casos do Peru e do Chile, as reservas territoriais para os indígenas disputam o espaço com empresas de mineração, de hidrocarbonetos ou madeireiras, e a indefinição política do Estado para definir um marco jurídico e uma institucionalidade legal coloca continuamente os indígenas em situação de insegurança individual e coletiva. 
No Brasil, na terra indígena Raposa Serra do Sol, demarcada e registrada para os povos indígenas depois de muitos anos de negociação e trâmite, as comunidades indígenas ainda são vitimadas pelo impulso migratório às suas regiôes, a concessão de áreas a empresas mineradoras, assentamentos urbanos e colonização agrícola, bem como projetos de obras hidrelétricas e de obras de uma base militar.

Finalmente, o relatório elaborado por Stavenhagen (2008) indica, sobre o México, a não implementação das disposições de reforma constitucional, decidida em 2001 com os indígenas, e cuja missão era realizar os compromissos governamentais definidos nos acordos de paz de 1996.

O relatório sobre Direitos Humanos e Liberdades Fundamentais dos Indigenas, de Stavenhagen (2008) sintetiza, assim, a diversidades de casos de flagrante violação aos direitos indígenas e de exemplos que retratam o claro descompasso entre os níveis da legislação internacional sobre direitos indígenas, o constitucionalismo latino-americano e legislação ordinária.

Conclui-se que há grave inconsistência legal e, muitas vezes, inexiste a legislação regulatória e secundária necessária. Também, há uma brecha de implementação entre a legislação existente e a prática administrativa, jurídica e política, cujas raízes são diversas: há pouca participação indígena na definição e realização das leis, a falta acompanhamento na aplicação das leis e das políticas públicas, e principalmente, há um aparato burocrático estatal inadequado, lento, de funcionamento não ajustado às demandas multiculturais e que carrega ainda o ranço assimilacionista e preconceituoso para tratar de direitos de minorias étnicas.

A despeito deste cenário crítico, é evidente que houve um desenvolvimento importante em matéria de direitos indígenas nos dois últimos decênios.

\section{Conclusão}

Quando T.H. Marshall (1967) tratou do desenvolvimento histórico da Cidadania, na sua consagrada obra Cidadania, Classes Sociais e Status, escrita em 1949 por motivo da Declaração Universal dos Direitos Humanos, ele observou que à medida que a sociedade de classes se desenvolvia dentro do capitalismo, também a cidadania moderna passava de um sistema de direitos, que nasce das relaçóes de mercado e as sustenta, para outro em que 
prevalecia um relacionamento antagônico da cidadania com a estrutura do sistema sócio-econômico. Com isso, ele queria dizer que o alargamento da cidadania tem a ver, não apenas, com as mudanças políticas no Estado, mas também com os conflitos entre instituiçóes e com as lutas entre grupos sociais.

A cidadania étnica parece ser um novo capítulo, o mais recente, desse processo de conquistas de direito, das necessárias transformaçóes no Estado e do embate que ocorre quando um segmento da sociedade, desta vez os indígenas, não se reconhece nas instituições de direito existentes. Isto porque as instituições não são suficientemente amplas para incluí-los e porque esta população já traz das suas comunidades seus princípios de organização política e produtiva, suas instituiçóes de justiça e suas fidelidades identitárias.

Procuramos demonstrar neste trabalho o desenvolvimento da cidadania étnica em que a questão indígena é transformada em agenda política para o governo, no foro interno, e para os Estados, nas arenas internacionais do direito. Na politização da questão étnica, foi observada a relação entre o desenvolvimento do Direito Internacional em matéria indígena, o recente constitucionalismo latino-americano dos dois últimos decênios, e a irrupçáo do novo movimento indígena com discursos que articulam as demandas tradicionais das comunidades indígenas com os desafios da sociedade capitalista globalizada.

Nas experiências analisadas, adverte-se a dificuldade de realizar as comparações entre Estados e movimentos sociais, dado o descompasso do desenvolvimento do direito indígena em cada país, de acordo com as experiências particulares e marcadas pelos tempos históricos diferenciados das lutas internas. Mesmo assim, foi possível identificar alguns aspectos que podem ser aqui destacados à guisa de conclusão.

Há um padrão de demanda dos movimentos indígenas que aponta para a defesa dos direitos de posse da terra e de autodeterminaçáo como dois momentos distintos, mas relacionados, da transformação da cidadania étnica. $\mathrm{O}$ primeiro defende as condiçóes materiais de existência e sobrevivência dos povos indígenas; o segundo define um horizonte político substantivo de atuação em relação ao Estado e à sociedade hegemônica. A partir desta base, aparentemente, articulam-se o resto das demandas locais, ora contra a violência física e o avanço do mercado nas suas comunidades, ora por 
cidadania social e políticas, expressadas em educação, saúde e participação nas decisões, ora pelas noçóes abstratas da identidade e da tradição cultural.

A análise que articula o direito internacional, as transformaçóes constitucionais e a ação indígena, de fato, está presente em toda a literatura especializada sobre o assunto. Contudo, observa-se o peso diferenciado de cada aspecto no cenário interno dos países da região, o que nos faz considerar que em alguns casos a cidadania étnica foi resultado da ação dos próprios atores envolvidos, mas em outros ela pode ter sido o legado do desenvolvimento internacional dos princípios de direito. Neste caso, a Convenção 169 e a Declaração Universal dos Direitos Indígenas, entre outros documentos importantes, constituem ao mesmo tempo a sintese dos debates globais na matéria, com aportes de todos os atores mobilizados mundo afora, e a base a partir da qual se dissemina o pensamento da cidadania étnica que orientará futuramente demandas e políticas públicas.

Tal é a principal contribuição ao direito indígena que ambas as experiências trouxeram: a possibilidade de ser ao mesmo tempo síntese das demandas e reflexóes sobre o assunto, e ser documento de princípios para setores e Estados menos mobilizados nesta temática, com o que se resolvem aspectos de fundamentação de direitos para as minorias étnicas não reconhecidas nos Estados nacionais.

O reconhecimento dos direitos, entretanto, não é suficiente, como era de se esperar, para transformar tanto uma cultura que desconsidera as diferenças na esfera pública como um sistema de poder que pode ver em risco seus interesses políticos e econômicos ao estender direitos a novas minorias. $\mathrm{Na}$ América Latina, esta condição assume um teor de dificuldade maior, dada a situação ainda fragilizada das suas democracias, da incipiente racionalidade das suas burocracias e, principalmente, dos exíguos recursos econômicos que impedem alguns países de atender as demandas de igualdade social.

A despeito desta conjuntura pouco alentadora e do cenário de recursos limitados, observa-se a não correspondência direta entre o amadurecimento da consciência de direito e a situação de extrema pobreza das suas populaçóes, como nos casos dos indígenas da Bolívia, do Equador e de Chiapas.

Ao mesmo tempo, verifica-se que o cenário para o desenvolvimento do direito destas populaçóes pode ser favorecido pela abertura democrática ou 
pela ocorrência histórica de um Estado com viés social, como no Brasil da reforma constitucional de 1988 e na Venezuela da era Chávez, capaz de desenvolver a estrutura necessária para a organização das minorias sociais e a abertura da esfera pública de direitos.

A cidadania étnica em desenvolvimento na América Latina não deve ser compreendida como um fenômeno isolado, mas uma tendência a partir da perspectiva da expansão da Declaraçáo Universal dos Direitos Humanos. Esta tendência tem se acentuado nos últimos anos com a maior preocupação de governos latino-americanos em garantir os direitos de cidadania a segmentos até entấo marginalizados, dentre os quais, os povos indígenas. $\mathrm{E}$ isto, por sua vez, deu nova dimensão à cidadania étnica. 


\section{Referências Bibliográficas}

ANDERSON, Benedict. Comunidades Imaginadas: reflexiones sobre el origen y la difusión del nacionalismo. México: Fondo de Cultura Económica, 1997.

ARENAS, Luis Carlos. A luta contra a exploração do petróleo no território U'wa: estudo de caso de uma luta local que se globalizou. In: SANTOS, Boaventura de Sousa. Reconhecer para libertar: os caminhos do cosmopolitismo multicultural. Rio de Janeiro: Civilização Brasileira, 2003.

BARIÉ, Cletus Gregor. Pueblos indígenas y derechos constitucionales en América Latina: un panorama. Bolívia: Comisión Nacional para el Desarrollo de los Pueblos Indígenas/Gobierno de México/Abya Yala/Banco Mundial, 2003.

BOBBIO, Norberto. A era dos Direitos. Rio de Janeiro: Ed. Elsevier, 2004.

BUENROSTRO; ARELLANO, Alejandro. As raizes do fenômeno Chiapas: o já basta da resistência zapatista. São Paulo: Alfarrabio, 2002.

COMISSÃO ECONÔMICA PARA A AMÉRICA LATINA. CEPAL. Pueblos indigenas y afrodescendientes de América Latina y el Caribe: información sociodemográfica para políticas y programas. Santiago: ONU, 2006.

. Panorama Social de América Latina. Santiago de Chile: ONU/CEPAL, 2006.

COMPARATO, Fábio Konder. A afirmação histórica dos Direitos Humanos. São Paulo: Saraiva, 2001.

CONDOR, Jorge. Sistema de Indicadores de las Nacionalidades y Pueblos del Ecuador (SIDENPE). In: CEPAL (Comissão Econômica para a América Latina). Pueblos indígenas y afrodescendientes de América Latina y el Caribe: Información sociodemográfica para políticas y programas. Santiago: ONU, 2006.

GALLEGOS, Franklin Ramirez. Las paradojas de la custión indíena en el Ecuador: etiquetamiento y control. Revista Nueva Sociedad, n. 176, p. 1723, dez. 2001. 
GARCIA SERRANO, Fernando. Política, Estado y diversidad cultural: la cuestión indígena en la región andina. Revista Nueva Sociedad, n. 173, p. 94-103, jun. 2001.

GOHN, Maria da Glória. Teorias dos movimentos sociais: paradigmas clássicos e contemporâneos. São Paulo: Loyola, 1997.

GUERRERO, Andrés. El levantamiento indígena de 1994: discurso y representación política en Ecuador. Revista Nueva Sociedad, n. 142, p. 94103, mar./abr. 1996.

GUERRERO BRAVO, Juan Carlos. Pasado, presente y futuro de las rondas campesinas antisubversivas en Junín, Perú (1990-2001). In: GIARRACCA, Norma; LEVY, Bettina (Comp.). Ruralidades Latinoamericanas: identidades y luchas sociales. Buenos Aires: Consejo Latinoamericano de Ciencias Sociales/CLACSO, 2004.

HALL, Gillete; PATRINOS, Harry Anthony. Pueblos indigenas, pobreza y desarrollo humano en América Latina: 1994-2004 (Resumen ejecutivo). Banco Mundial/Mayo Ediciones. Disponível em: http://wbln0018.worldbank. org/LAC/ lacinfoclient.nsf/8d6661f6799ea8a48525673900537f95/ 3 b b 82428 d d 9 d bea 785257004007 c 113 d/ \$ F I L E / PueblosIndigenasPobreza_resumen_es.pdf. Acesso em: 13/05/2008.

INSTITUTO NACIONAL DE ESTADÍSTICA DE BOLIVIA. INE Estadisticas Nacionales 2002. Bolívia: INE, 2002.

KYMLICKA, Will. Ciudadanía multicultural. Buenos Aires: Paidós, 1996.

LARAÑA, Enrique. La construcción dos movimientos sociales. Madrid: Alianza Editorial. 1999.

LARAÑA, Enrique; GUSFIELD, Joseph. Los nuevos movimientos sociales: de la ideología a la identidad. Madrid: Centro de Investigaciones Sociológicas, 1994.

MARÉS, Carlos Frederico de Souza Filho. O renascer dos povos indígenas para o Direito. Curitiba: Ed. Juruá, 1998. 
. Multiculturalismo e direitos coletivos. In: SANTOS, B. S. Reconhecer para libertar: os caminhos do cosmopolitismo multicultural. Rio de Janeiro: Civilização Brasileira, 2003.

MARIOTTI, Daniela. El conflicto por la tierra de las comunidades aborígenes Kollas (Argentina) y Mapuche-Pehuenche (Chile): discursos globales en escenarios locales. In: GIARRACCA, Norma; LEVY, Bettina (Comp.). Ruralidades latinoamericanas: identidades y luchas sociales. Buenos Aires: Consejo Latinoamericano de Ciencias Sociales/CLACSO, 2004.

MARSHALL, Theodore H. Cidadania. Classes sociais e status. Rio de Janeiro: Zahar, 1967.

PROGRAMA DE LAS NACIONES UNIDAS PARA EL DESARROLLO. PNUD Segundo informe sobre desarrollo humano en Centroamérica y Panamá. PNUD/ONU, 2004.

PSACHAROPOULOS, George; PATRINOS, Harry Anthony. Pueblos indigenas y pobreza en América Latina. Washington, D.C.: Banco Mundial, 1994.

RENSHAW, Jonathan; WRAY, Natalia. Indicadores de bienestar e pobreza indigena. Banco Interamericano de Desarrollo, 2004.

SAINT-PIERRE, Héctor Luis. A politica armada: fundamentos da guerra revolucionária. São Paulo: UNESP, 2000.

SANTOS, Boaventura Sousa. Os novos movimentos sociais. In: LEHER, Roberto; SETÚBAL, Mariana (Org.). Pensamento crítico e movimentos sociais. Diálogos para uma nova práxis. São Paulo: Cortez, 2005.

SIEDER, Rachel. Multiculturalism in Latin America: indigenous rights, diversity and democracy. Inglaterra: Palgrave/ILAS, 2002.

STAVENHAGEN, Rodolfo. Los pueblos indígens y sus derechos: informes temáticos del relator especial sobre la situación de los Derechos Humanos y las libertades fundamentales de los pueblos indígenas del Consejo de Derechos Humanos de la Organización de las Naciones Unidas (20022007). México: Unesco. Disponível em: http://eib.sep.gob.mex/files/libro_ stavenhagen_unesco.pdf Acesso em: 10/03/2008.

URQUIDI, Vivian. Movimento cocaleiro na Bolívia. São Paulo: Hucitec, 2007. 